\title{
Avaliação das Farinhas de Peixe e Pena, no Confinamento de Bezerros Leiteiros Desmamados, Através de Dietas Calculadas em Termos de Proteína Bruta ou de Proteína Metabolizável
}

\author{
Marcus Vinicius Morais de Oliveira ${ }^{1}$, Luis Maria Bonecarrère Sanchez ${ }^{2}$, \\ Fernando Miranda Vargas Júnior ${ }^{3}$, Juan Ramón Olaquiaga Pérez ${ }^{4}$, Cleber Cassol Pires ${ }^{2}$, \\ lone Maria Pereira Haygert ${ }^{5}$, Adriana Frizzo ${ }^{6}$, Rogério de Paula Lana ${ }^{7}$
}

\begin{abstract}
RESUMO - Os objetivos deste trabalho foram avaliar três fontes protéicas - o farelo de soja e as farinhas de peixe e de pena - e dois métodos de cálculo de rações - o calculado em termos de proteína bruta (PB), segundo recomendações do NRC (1988), e o proposto pelo AFRC (1993), calculado em termos de proteína metabolizável (PM) - através do desempenho de bezerros leiteiros. Os animais foram confinados e submetidos a cinco dietas, que variavam apenas as fontes protéicas em sua composição, assim discriminadas: FS- Farelo de Soja, FPx- Farinha de Peixe, FPn- Farinha de Pena, FPxU- Farinha de Peixe e Uréia, e FPnU- Farinha de Pena e Uréia. Forneceu-se uma dieta completa, composta de $40 \%$ de silagem de sorgo e $60 \%$ de concentrado, na MS. Todos os tratamentos possuíam cerca de 2,56 Mcal/kg MS de energia metabolizável, sendo os tratamentos FS, FPx e FPn calculados pelo sistema de PB, possuindo 18\% de PB, e os tratamentos FPxU e FPnU, calculados pelo sistema de PM, possuindo 16,3\% de PB e uma mesma quantidade de proteína metabolizável que o tratamento FS, com 112,0 gramas de $\mathrm{PM}$ /dia. Individualmente, os tratamentos não apresentaram diferenças significativas $(\mathrm{P}>0,05)$ no peso vivo final, no ganho de peso diário e no consumo de matéria seca, havendo diferenças apenas na conversão alimentar. A melhor conversão alimentar ocorreu no tratamento FPx, e a pior, no tratamento FPnU. Concluiu-se que o método de cálculo utilizando PM proporcionou resultados semelhantes aos do método de PB. Os tratamentos com farinha de peixe proporcionaram maiores ganhos de peso, menores consumos e melhor conversão alimentar que os tratamentos com farinha de pena, permanecendo o tratamento farelo de soja com o ganho de peso intermediário.
\end{abstract}

Palavras-chave: AFRC, desempenho, terneiros

\section{Evaluation of Fish and Feather Meals for Confined Dairy Calves Weaned Through Diets Calculated in Terms of Crude Protein or Metabolizable Protein}

\begin{abstract}
The objectives of this work were to evaluate three protein sources - soybean meal, fish meal and feather meal - and two methods of calculation of rations - the calculated in terms of crude protein (CP), according to recommendations of NRC (1988); and the proposed by the AFRC (1993), and calculated in terms of metabolizable protein (MP) - through the performance of calves. The animals were confined and submitted to five diets, that varied only protein sources in its composition, thus discriminated: SM- Soybean Meal, FsM- Fish Meal, FeM- Feather Meal, FsMU- Fish Meal and Urea, and FeMU Feather Meal and Urea. A complete diet was supplied, composed of $40 \%$ of sorghum silage and $60 \%$ of concentrate. All treatments possessed about of $2.56 \mathrm{Mcal} / \mathrm{kg}$ DM of metabolizable energy, being the treatments SM, FsM and FeM calculated by the system of CP, with $18 \%$ of CP, and the treatments FsMU and FeMU, calculated by the system of MP, with $16.3 \%$ of CP and a same amount of metabolizable protein than the treatment SM, with 112.0 grams of MP/ day. Individually, the treatments did not present significant differences $(\mathrm{P}>0.05)$ in the final alive weight, in daily gain weight and in dry matter intake, having differences only in the feed:gain ratio. The best feed:gain ratio happened in the treatment FsM and the worst in the treatment FeMU. It is concluded that the MP method provides similar results to the method of CP. The treatments with fish meal provide larger weight gains, smaller intake and better feed:gain ratio than the treatments with feather meal, staying the treatment soybean meal with intermediary daily gain.
\end{abstract}

Key Words: AFRC, feedlot, performance

\footnotetext{
Zootecnista - Estudante de Doutorado na Universidade Federal de Viçosa (UFV) - MG. Endereço: Avenida Santa Rita, n. 110 apto 201 - Centro, Viçosa-MG. CEP 36.570.000. Email: marcusvm@alunos.ufv.br

2 Professor Titular do Departamento de Zootecnia da Universidade Federal de Santa Maria (UFSM) - RS.

3, 6 Zootecnista - Doutorando em Zootecnia na UNESP/Botucatu, UFRGS/Porto Alegre, respectivamente.

Professor Titular do Departamento de Zootecnia da Universidade Federal de Lavras (UFLA) - MG.

Mestre em Produção Animal.

Professor do Departamento de Zootecnia da Universidade Federal de Viçosa (UFV) - MG.
} 


\section{Introdução}

A baixa concentração de nitrogênio solúvel no rúmen afeta o crescimento microbiano, diminui a digestão da fibra e limita o consumo. Isso é verificado quando se fornecem dietas com teores protéicos crescentes a animais jovens, havendo assim aumento no desempenho (Veira et al., 1980a,b; Bagg et al., 1985). Todavia, a quantidade de proteína dietética não deve ser fornecida de forma indiscriminada ou excessiva, já que um aumento no teor protéico, utilizando principalmente fontes de elevada solubilidade, promove intensa degradação dos aminoácidos no rúmen, sem que estes sejam aproveitados eficientemente pelos microrganismos. Assim, todo o excesso de amônia é eliminado através da urina com um custo energético, havendo, portanto, pequeno aumento na quantidade de aminoácidos que chega ao intestino (Church, 1993).

De acordo com McDonald (1954) e Annison et al. (1954), a caseína sofre fermentação ruminal ao redor de noventa por cento. No entanto, quando fontes protéicas com elevado valor biológico são colocadas através de infusões abomasais, verificam-se notáveis aumentos na produção de lã, na retenção de nitrogênio, na produção de leite e no ganho de peso dos animais (Reis \& Schinckel, 1963, 1964; Chalupa et al., 1972; Derrig et al., 1973). Ferguson et al. (1967) também estabeleceram que, para se aumentar a produção de lã ou obter elevadas taxas de crescimento, é necessário fornecer elevada quantidade de proteína passante, sem que ocorram no entanto prejuízos no crescimento microbiano. Já Chalupa (1975) adverte que a utilização de alimentos com baixa degradabilidade ruminal somente apresenta resposta positiva no caso de animais que necessitem de mais aminoácidos para atender os seus requerimentos de mantença e produção, seja por deposição de tecido magro, produção de leite ou lã. Entretanto, se o fornecimento de aminoácidos vindo dos microrganismos for suficiente, as respostas poderão ser insignificantes ou, ainda, negativas.

Segundo Church (1984), os alimentos protéicos de origem animal são aqueles que possuem a maior quantidade de proteína naturalmente passante. Contudo, reconhece-se que a qualidade de seus aminoácidos pode ser bastante diferenciada, devido à variabilidade entre as partidas e aos diferentes métodos de processamento empregados na indústria. Dentre estes alimentos a farinha de peixe destaca-se, devido ao seu grande valor biológico e ao elevado conteúdo de aminoácidos essenciais, sendo ainda rica em vitaminas, principalmente a B12, em ácidos graxos e minerais (Blas et al., 1987). A farinha de pena também é considerada uma fonte protéica valiosa, em razão do seu elevado teor protéico e do baixo custo por unidade de proteína, sendo rica em aminoácidos sulfurados, principalmente cisteína (Rakes et al., 1968).

Respostas positivas, com a utilização de farinha de peixe em dietas para ruminantes, têm sido relatadas por Garstang et al. (1979), Veira et al. (1985) e Hassan \& Bryant (1986). Algumas pesquisas, no entanto, revelam uma falta de resposta, como foi demonstrado por Gontijo Filho et al. (1977) e Keyserlingk \& Mathison (1993). Pesquisas com farinha de pena hidrolisada como fonte protéica para ruminantes são limitadas, e a sua utilização normalmente gera respostas semelhantes ou inferiores ao outro suplemento no qual a farinha foi comparada, sendo isso comprovado por Jordan \& Jordan (1955), Brow \& Pate (1997) e Jauris (1998).

Os requerimentos protéicos dos ruminantes, durante muitos anos, foram estudados apenas em termos de proteína bruta ou de proteína bruta digestível. Entretanto, esses parâmetros passaram a ser inadequados e insatisfatórios, já que nenhum deles leva em conta a estreita relação existente entre a necessidade de nitrogênio solúvel no rúmen e a quantidade de energia consumida fermentada no rúmen (National Research Council - NRC, 1996). Visando aperfeiçoar uma metodologia mais adequada para a determinação das exigências protéicas dos ruminantes, vários países desenvolveram sistemas próprios de cálculos de rações, em que se separam as necessidades dos microrganismos e as do animal hospedeiro. Dessa forma, tentou-se maximizar a eficiência microbiana, não permitindo que a proteína alimentar fosse sub ou superfermentada no rúmen. A Inglaterra, por intermédio do AFRC (1993), propôs um sistema baseado na proteína metabolizável, sendo esta formada pelo somatório da proteína microbiana verdadeira digerível mais a proteína alimentar não degradável no rúmen, mas digerível no intestino.

Os objetivos deste trabalho foram avaliar três fontes protéicas - o farelo de soja e as farinhas de peixe e de pena - e dois métodos de cálculo de rações, calculados em termos de proteína bruta ou proteína metabolizável, através do consumo de matéria seca, do ganho de peso e da conversão alimentar de bezerros leiteiros desmamados. 


\section{Material e Métodos}

Este trabalho foi desenvolvido nos setores de Nutrição Animal e de Gado de Leite, ambos pertencentes ao Departamento de Zootecnia da Universidade Federal de Santa Maria, no município de Santa Maria, no Rio Grande do Sul. Utilizaram-se 25 bezerros puros, machos inteiros, sendo cinco da raça jérsei e 20 da raça holandesa. Esses animais foram desmamados precocemente, aos 42 dias, e iniciaram o experimento com 60 dias de vida, sendo o período experimental de oito semanas e variável com a data de nascimento.

Os animais foram blocados primeiramente pela sua raça, seguidos por época de nascimento e peso vivo. Formaram-se cinco blocos, sendo cada um composto por cinco animais. Dois blocos foram mantidos em uma bezerreira convencional, construída de alvenaria, com aberturas nas laterais e internamente dividida em baias individuais de $1,60 \mathrm{~m}^{2}$, com um corredor central. Os outros três foram mantidos na parte coberta de um galpão de confinamento, sendo os animais presos individualmente por meio de uma corda, com cerca de 2,5 metros. Ambas as instalações permitiam que cada bezerro tivesse acesso individualizado a um cocho e um balde com água.

As instalações permaneceram em um vazio sanitário de três meses e foram posteriormente desinfetadas com uma solução de água e cal virgem. Todos os animais foram protegidos contra ecto e endoparasitas, sendo também fornecido um grama de ionóforo (lasalocida sódica) por animal por dia, como medida preventiva para evitar diarréias provocadas por eimeriose. Os animais receberam ainda uma dose intramuscular de complexo vitamínico (vitaminas A, D e E).

Foram estudadas cinco dietas, e a variação na formulação entre elas se deu apenas entre as fontes protéicas, assim discriminadas: FS- Farelo de Soja, FPx- Farinha de Peixe, FPn- Farinha de Pena, FPxU- Farinha de Peixe com Uréia e FPnU- Farinha de Pena com Uréia. Todos os animais receberam como volumoso silagem de sorgo da variedade $\mathrm{AG}$ 2002. Forneceu-se uma dieta completa à vontade, a qual mantinha uma relação de $40 \%$ de volumoso e $60 \%$ de concentrado, na matéria seca. As dietas foram formuladas de modo que todos os ingredientes fossem fixos, com exceção do milho e da fonte protéica.
Todas as dietas foram formuladas para apresentarem teores semelhantes de energia metabolizável e proteína, com cerca de 2,56 Mcal/ $\mathrm{kg}$ MS, sendo os tratamentos FS, FPx e FPn com $18 \%$ de PB calculados através do método convencional, segundo as recomendações de PB descritas no NRC (1988). Já os cálculos dos tratamentos FPxU e FPnU foram baseados no sistema inglês, descrito no AFRC (1993). A produção microbiana foi ajustada de acordo com a fermentação ruminal, adicionando-se uréia, já que essas dietas eram deficientes em nitrogênio potencialmente degradável em nível ruminal, devido à baixa solubilidade das farinhas de peixe e pena. O valor protéico médio de 16,3\% das dietas FPxU e FpnU foi uma conseqüência da dieta calculada por meio de equações descritas no AFRC (1993). Portanto, as quantidades de proteínas passantes foram semelhantes entre estas duas dietas, diferenciando-as apenas na qualidade dos seus aminoácidos. Além disso, os tratamentos FPxU e FPnU guardaram uma relação de proteína metabolizável de 112,5 gramas de $\mathrm{PM} /$ dia semelhante ao tratamento FS. A composição dos tratamentos FS, FPx, FPn, FPxU e FPnU encontra-se na Tabela 1.

O consumo de matéria seca foi determinado através da diferença entre o alimento oferecido menos as sobras. Desse modo, tanto os alimentos oferecidos como as sobras eram coletados diariamente, pesados e amostrados. As amostras eram congeladas por sete dias, formando uma amostra composta por baia. Posteriormente, realizaram-se análises dos teores de MS da semana por baia, conforme metodologia descrita por Silva (1990). Também foi analisado o teor protéico dos alimentos utilizados nas dietas, sendo os teores de proteína bruta, proteína e energia metabolizável, energia fermentecível, proteína efetivamente degradável, proteína não degradável no rúmen mas digestível no intestino e proteína bruta microbiana calculados de acordo com o AFRC (1993), para uma velocidade de passagem de $5 \% /$ hora (Tabela 2 ).

O delineamento utilizado foi em blocos casualizados, com cinco tratamentos e cinco repetições. Procedeu-se à análise de variância, teste de Tukey, estudos de contrastes ortogonais e análise fatorial utilizando-se o pacote estatístico SAS Statistic Analysis System (1990). 
Tabela 1- Composição percentual, na matéria seca, das dietas farelo de soja (FS), farinha de peixe (FPx), farinha de pena (FPn), farinha de peixe mais uréia (FpxU) e farinha de pena mais uréia (FpnU)

Table 1 - Percentage composition, in dry matter, of the diets soybean meal (SM), fish meal (FsM), feather meal (FeM), fish meal more urea (FsMU) and feather meal more urea (FeMU)

\begin{tabular}{|c|c|c|c|c|c|}
\hline \multirow[t]{2}{*}{$\begin{array}{l}\text { Ingredientes } \\
\text { Ingredients }\end{array}$} & \multicolumn{5}{|c|}{$\begin{array}{l}\text { Tratamentos } \\
\text { Treatments }\end{array}$} \\
\hline & $\begin{array}{l}\text { FS } \\
S M\end{array}$ & $\begin{array}{l}\text { FPx } \\
F s M\end{array}$ & $\begin{array}{l}\text { FPn } \\
\text { FeM }\end{array}$ & $\begin{array}{l}\text { FPxU } \\
F s M U\end{array}$ & $\begin{array}{l}\text { FpnU } \\
\text { FeMU }\end{array}$ \\
\hline $\begin{array}{l}\text { Silagem sorgo } \\
\text { Sorghum silage }\end{array}$ & 40,0 & 40,0 & 40,0 & 40,0 & 40,0 \\
\hline $\begin{array}{l}\text { Melaço } \\
\text { Molasses }\end{array}$ & 1,2 & 1,2 & 1,2 & 1,2 & 1,2 \\
\hline $\begin{array}{l}\text { Farelo arroz } \\
\text { Rice meal }\end{array}$ & 8,8 & 8,8 & 8,8 & 8,8 & 8,8 \\
\hline $\begin{array}{l}\text { Grão milho } \\
\text { Grain corn }\end{array}$ & 17,4 & 28,0 & 30,8 & 34,9 & 37,5 \\
\hline $\begin{array}{l}\text { Farelo soja } \\
\text { Soybean meal }\end{array}$ & 31,1 & - & - & - & - \\
\hline $\begin{array}{l}\text { Farinha peixe } \\
\text { Fish meal }\end{array}$ & - & 20,5 & - & 12,6 & - \\
\hline $\begin{array}{l}\text { Farinha pena } \\
\text { Feather meal }\end{array}$ & - & - & 17,7 & - & 9,8 \\
\hline $\begin{array}{l}\text { Uréia } \\
\text { Urea }\end{array}$ & - & - & - & 1,0 & 1,2 \\
\hline $\begin{array}{l}\text { Mistura mineral } \\
\text { Mineral salt }\end{array}$ & 1,5 & 1,5 & 1,5 & 1,5 & 1,5 \\
\hline
\end{tabular}

Tabela 2 - Valores de proteína bruta (PB), proteína metabolizável (PM), energia metabolizável (EM), energia fermentecível $(E F)$, proteína efetivamente degradável no rúmen (PEDR), proteína não degradável mas digerível (PNDD) e proteína bruta microbiana (PBM), das dietas FS, FPx, FPn, FPxU e FpnU ${ }^{1}$

Table 2 - Values of crude protein (CP), metabolizable protein (MP), metabolizable energy (ME), fermented metabolizable energy $(F M E)$, effective rumen degradable protein (ERDP), digestible undegraded protein (DUP) and microbial crude protein $(M C P)$, of the diets SM, FsM, FeM, FsMU and FeMU 1

\begin{tabular}{lcccc}
\hline Variáveis & \multicolumn{3}{c}{ Tratamentos } \\
Variables & \multicolumn{2}{c}{ Treatments } & FPxU \\
\cline { 2 - 5 } & FS & FPx & FPn & FpnU \\
FeMU
\end{tabular}

${ }_{1}^{1}$ FS- farelo de soja, FPx- farinha de peixe, FPn- farinha de pena, FpxU- farinha de peixe mais uréia, FpnU- farinha de pena mais uréia. ${ }^{1}$ SM- soybean meal, FsM- fish meal, FeM-feather meal, FsMU- fish meal more urea, FeMU-feather meal more urea. 


\section{Resultados e Discussão}

$\mathrm{Na}$ Tabela 3 encontram-se os valores da concentração de proteína contida na dieta efetivamente degradável no rúmen (PED), da proteína consumida que foi degradada no rúmen (PCD), da concentração de proteína alimentar não degradável no rúmen (PND) e da proteína consumida que não foi degradada no rúmen $(\mathrm{PCND})$, para uma velocidade de passagem de 5 e $8 \%$ /hora. A PED e a PND foram calculadas segundo as fórmulas descritas no AFRC (1993), e a PCD e a PCND, de acordo com o consumo dos animais em relação aos valores ponderais da dietas, com suas respectivas PED e PND, dos tratamentos FS, FPx, FPn, FPxU e FpnU.

A concentração dietética de PED diminuiu com o aumento da velocidade de passagem para os tratamentos FS, FPx e FPn, mas essa diminuição quase não se verificou nos tratamentos FPxU e FpnU. Ocorreu o inverso com a concentração da PND com todos os tratamentos. Já a PCD e a PCND também seguiram o mesmo tipo de aproveitamento que a PED e a PND. No entanto, com a velocidade de passagem de $8 \%$ /hora, a quantidade de PCND do tratamento com FS foi semelhante à das outras dietas, indicando que, quanto maior a velocidade de passagem maior foi a quantidade de farelo de soja disponível no intestino e menores foram as diferenças desse alimento em relação às dietas com farinhas de peixe e pena.

O peso vivo, o ganho de peso diário, o consumo de matéria seca e a conversão alimentar são apresentados na Tabela 4. Apesar de entrarem no experimento com um peso vivo inicial médio de $57,0 \mathrm{~kg}$, considerado baixo, os animais atingiram peso vivo final médio de $102,0 \mathrm{~kg}$, considerado ideal para essa categoria. Isso ocorreu devido ao bom ganho de peso diário que estes animais conseguiram acumular ao longo do experimento, com média de $0,8 \mathrm{~kg}$. Verifica-se que o peso vivo e o ganho de peso diário não foram afetados pelas fontes protéicas ou pelos métodos de cálculo das dietas. Apesar de não diferir significativamente, observa-se uma tendência das dietas com farinha de peixe apresentaram melhores ganhos de peso, em ambos os sistemas de cálculo, e a farinha de pena pior ganho que o farelo de soja no sistema NRC (1988); contudo, isso se inverteu no sistema de proteína metabolizável, em que a dieta com farinha de pena

Tabela 3 - Concentração de proteína dietética efetivamente degradável no rúmen (PED) e da proteína dietética não degradável no rúmen (PND), quantidade de proteína consumida degradável (PCD) e da proteína consumida não degradável no rúmen (PCND), dos tratamentos FS, FPx, FPn, FPxU e FpnU1

Table 3 - Concentration of dietary crude protein effectively degradable in the rumen (CPED), of degradable intake protein (DIP), dietary non degradable protein (NDP) and non degradable intake protein (NDIP) of the treatments SM, FsM, FeM, FsMU and $F e M U^{1}$

\begin{tabular}{|c|c|c|c|c|c|}
\hline \multirow[t]{2}{*}{$\begin{array}{l}\text { Variáveis } \\
\text { Variables }\end{array}$} & \multicolumn{5}{|c|}{$\begin{array}{c}\text { Tratamentos } \\
\text { Treatments }\end{array}$} \\
\hline & $\begin{array}{l}\text { FS } \\
S M\end{array}$ & $\begin{array}{l}\text { FPx } \\
F s M\end{array}$ & $\begin{array}{l}\text { FPn } \\
\text { FeM }\end{array}$ & $\begin{array}{l}\text { FPxU } \\
F s M U\end{array}$ & $\begin{array}{l}\text { FpnU } \\
F e M U\end{array}$ \\
\hline $\begin{array}{l}\text { PED g/kg MS - 5\%/hora } \\
C P E D \mathrm{~g} / \mathrm{kg} D M-5 \% / \text { hour }\end{array}$ & 98,2 & 70,9 & 68,0 & 79,2 & 79,6 \\
\hline $\begin{array}{l}\text { PED g/kg MS - 8\%/hora } \\
C P E D \text { g/kg DM - 8\%/hour }\end{array}$ & 82,8 & 64,4 & 62,7 & 79,1 & 79,0 \\
\hline $\begin{array}{l}\text { PCD g consumida MS/dia - } 5 \% / \text { hora } \\
\text { DIP g intake DM/day - } 5 \% / \text { hour }\end{array}$ & 251,4 & 172,3 & 151,6 & 194,8 & 220,5 \\
\hline $\begin{array}{l}\text { PCD g consumida MS/dia - } 8 \% / \text { hora } \\
\text { DIP g intake DM/day - } 8 \% / \text { hour }\end{array}$ & 211,9 & 156,5 & 139,8 & 194,6 & 218,8 \\
\hline $\begin{array}{l}\text { PND g/kg MS - 5\%/hora } \\
N D P \mathrm{~g} / \mathrm{kg} \mathrm{DM}-5 \% / \text { hour }\end{array}$ & 73,8 & 97,4 & 106,3 & 70,0 & 70,6 \\
\hline $\begin{array}{l}\text { PND g/kg MS - 8\%/hora } \\
N D P \mathrm{~g} / \mathrm{kg} D M-8 \% / \text { hour }\end{array}$ & 89,1 & 104,0 & 111,6 & 75,6 & 75,3 \\
\hline $\begin{array}{l}\text { PCND g consumida MS/dia - } 5 \% / \text { hora } \\
\text { NDIP g intake DM/day - } 5 \% / \text { hour }\end{array}$ & 188,9 & 236,7 & 237,4 & 172,2 & 195,6 \\
\hline $\begin{array}{l}\text { PCND g consumida MS/dia - } 8 \% / \text { hora } \\
\text { NDIP g intake DM/day - } 8 \% / \text { hour }\end{array}$ & 228,1 & 252,7 & 248,9 & 186,0 & 208,6 \\
\hline
\end{tabular}

$\overline{1}$ FS - farelo de soja, FPx- farinha de peixe, FPn - farinha de pena, FpxU - farinha de peixe mais uréia, FpnU - farinha de pena mais uréia.

${ }^{1}$ SM - soybean meal, FsM- fish meal, FeM - feather meal, FsMU - fish meal more urea, FeMU - feather meal more urea. 
tendeu a ser levemente superior à do farelo de soja. Esses resultados concordam com os de Zerbini \& Polan (1985), Steen (1992) e White et al. (1992), os quais verificaram que dietas com farelo de soja e com a farinha de peixe promoviam taxas de ganho de peso semelhantes. No entanto, Rocha et al. (1995) e Davenport et al. (1990) verificaram que o desempenho de animais que consumiam a farinha de peixe era maior do que o daqueles que consumiam o farelo de soja. Wray et al. (1979) e Jordan \& Croom (1957) também não verificaram diferenças no desempenho de animais suplementados com a farinha de pena ou com o farelo de soja.

Esses resultados semelhantes entre as fontes protéicas possivelmente se mantiveram devido à influência da velocidade de passagem. Esta não foi medida, mas pode-se supor que foi elevada em razão do consumo que ocorreu, como mostrado na Tabela 4, em percentagem de peso vivo, com cerca de 3,13\% de média. O sistema proposto pelo AFRC (1993), que leva em conta as necessidades microbianas e as requeridas pelo animal hospedeiro, teoricamente deveria ter promovido melhor desempenho nos animais, principalmente porque se utilizaram animais jovens, que possuem requerimentos protéicos proporcionalmente mais elevados que os energéticos. En- tretanto, isto não foi verificado, já que, de acordo com a Tabela 4, a única diferença estatística que ocorreu foi com a conversão alimentar, apesar de haver tendência de a dieta com farinha de peixe promover o maior ganho de peso e de a farinha de pena mais uréia ser superior à farinha de pena sozinha. Esses resultados são coerentes com os descritos por Sloan et al. (1988), que encontraram respostas semelhantes para dietas calculadas de acordo com o ARC Agricultural Research Council (1980), utilizando-se o farelo de soja e a farinha de peixe, em relação à produção de leite de vacas. Beever \& Cottrill (1994) também sugerem a importância de verificar se as proteínas passantes não estão sendo supervalorizadas no sistema do AFRC (1993), uma vez que as respostas dos animais são algumas vezes semelhantes, independentemente da fonte protéica utilizada, seja ela de baixa ou de alta degradabilidade.

Mesmo não ocorrendo desempenho superior dos animais que foram alimentados com as dietas FPxU e FPnU, houve redução média de $42 \%$ da quantidade das farinhas de peixe e pena que compunham a dieta. Com isso, houve redução dos custos dessas dietas, principalmente naquela com a farinha de peixe, na qual o consumo em relação ao peso vivo se manteve constante, em torno de $3,0 \%$, para os tratamentos

Tabela 4 - Peso vivo inicial (PVI) e final (PVF); ganho de peso médio diário (GMD); consumo de matéria seca, expresso em $\mathrm{kg} / \mathrm{dia}$ (CMS), em \% do peso vivo (CMSPV) e em função do peso metabólico (CMSPM); e conversão alimentar (CA) dos tratamentos FS, FPx, FPn, FPxU e FpnU ${ }^{1}$

Table 4 - Initial live weight (ILW), final live weight (FLW), average daily weight gain (ADWG), dry matter intake (DMI), dry matter intake in relation to the live weight (DMILW), dry matter intake in relation to the metabolic weight (DMIMW) and the feed:gain ratio (FGR) of the treatments SM, FSM, FeM, FSMU and FeMU ${ }^{1}$

\begin{tabular}{|c|c|c|c|c|c|c|c|}
\hline Item & $\begin{array}{l}\text { FS } \\
S M\end{array}$ & $\begin{array}{l}\text { FPx } \\
\text { Fs }\end{array}$ & $\begin{array}{l}\text { FPn } \\
\text { FeM }\end{array}$ & $\begin{array}{l}\text { FPxU } \\
F s M U\end{array}$ & $\begin{array}{l}\text { FPnU } \\
\text { FeMU }\end{array}$ & $\begin{array}{l}\text { Média } \\
\text { Average }\end{array}$ & CV\% \\
\hline $\begin{array}{l}\text { PVI - kg } \\
I L W-k g\end{array}$ & 57,88 & 55,98 & 54,18 & 57,34 & 59,74 & 57,02 & 8,41 \\
\hline $\begin{array}{l}\mathrm{PVF}-\mathrm{kg} \\
F L W-k g\end{array}$ & 100,48 & 108,00 & 91,74 & 105,08 & 102,90 & 101,64 & 11,07 \\
\hline $\begin{array}{l}\text { GMD - kg } \\
A D W G-k g\end{array}$ & 0,761 & 0,929 & 0,671 & 0,853 & 0,771 & 0,797 & 18,83 \\
\hline $\begin{array}{l}\text { CMS - kg MS/animal/dia } \\
\text { DMI - kg DM/animal/day }\end{array}$ & 2,56 & 2,43 & 2,23 & 2,46 & 2,75 & 2,49 & 14,61 \\
\hline $\begin{array}{l}\text { CMSPV - kg MS/100kg peso vivo } \\
D M I L W-k g D M / 100 g k \text { of } L W\end{array}$ & 3,23 & 2,96 & 3,06 & 3,03 & 3,38 & 3,13 & 10,12 \\
\hline $\begin{array}{l}\text { CMSPM - g MS/(PV })^{0,75} \\
D M I M W-g D M /(L W)^{0.75}\end{array}$ & 96,43 & 89,18 & 89,33 & 90,93 & 101,55 & 93,48 & 10,62 \\
\hline $\begin{array}{l}\mathrm{CA} \\
F G R\end{array}$ & $3,36^{\mathrm{a}}$ & $2,61^{\mathrm{c}}$ & $3,32^{\mathrm{ab}}$ & $2,88^{b c}$ & $3,57^{\mathrm{a}}$ & 3,15 & 10,83 \\
\hline
\end{tabular}

${ }^{1}$ FS - farelo de soja, FPx- farinha de peixe, FPn - farinha de pena, FpxU - farinha de peixe mais uréia, FpnU - farinha de pena mais uréia.

1 SM - soybean meal, FSM - fish meal, FeM - feather meal, FsMU - fish meal more urea, FeMU - feather meal more urea.

* Letras diferentes indicam diferenças significativas $(P<0,05)$ de acordo com o teste Tukey.

* Different letters indicate significant differences $(P<0.05)$ in agreement with the Tukey test.

\section{R. Bras. Zootec., v.31, n.3, p.1571-1581, 2002 (suplemento)}


FPx e FPxU. Além disso, o teor protéico das dietas foi reduzido de 18,0 para $16,2 \%$ de proteína bruta, indicando, portanto, que o sistema de proteína metabolizável é mais coerente que o sistema de proteína bruta. Contudo, há necessidade de mais investigações, devendo, portanto, ser utilizado com prudência.

O consumo total de matéria seca (silagem mais concentrado) foi elevado em todas as dietas, sendo estimulado possivelmente pela inclusão de $2,0 \%$ de melaço no concentrado. Não foi verificada nenhuma diferença no consumo, independentemente da forma expressa. Houve, no entanto, leve tendência de o tratamento com farinha de pena ser menos consumido e de o tratamento com farinha de pena mais uréia ser mais ingerido. Esses dados estão de acordo com Steen (1989) e Veira et al. (1994), que compararam o farelo de soja e a farinha de peixe e não constataram diferenças significativas na ingestão total de matéria seca. No entanto, Thomas et al. (1980) verificaram que a farinha de peixe estimulava o consumo de silagem, sendo o consumo de matéria seca total aumentado em 8\%. England \& Gill (1985) e Sanderson et al. (1992) também verificaram que o aumento da farinha de peixe na dieta aumentava linearmente a ingestão de matéria seca total. Entretanto, de acordo com Wray et al. (1979, 1980), quantidades crescentes de farinha de pena não estimulam o consumo de matéria seca, sendo observados consumos semelhantes nos animais que consumiam a farinha de pena ou o farelo de soja; esses resultados são coerentes com os obtidos neste experimento.

Já a melhor conversão alimentar, de 2,61 kg MS ingerida/kg de ganho de peso vivo, foi proporcionada pela dieta FPx. No entanto, ela foi estatisticamente semelhante à dieta FpxU, com 2,88 kg MS ingerido/kg de ganho de peso vivo. A dieta FPnU ficou com a pior conversão alimentar, de $3,57 \mathrm{~kg}$ MS ingerida $/ \mathrm{kg}$ de ganho de peso vivo, sendo, todavia, estatisticamente semelhante as dietas FPn e FS. Os tratamentos FPn e FPxU também foram estatisticamente iguais.

Resultados semelhantes também foram determinados por Brosh et al. (1990), Petit et al. (1991) e Rocha et al. (1995), que constataram uma melhor conversão alimentar para os animais alimentados com a farinha de peixe, quando comparada com o farelo de soja. No entanto, Smith et al. (1985), Steen (1985) e Comerford et al. (1992) observaram conversões alimentares semelhantes para a farinha de peixe e o farelo de soja. Melhores conversões alimentares para animais alimentados com farinha de pena, em relação ao farelo de soja, foram verificadas por Goedeken et al. (1990 a,b), embora as diferenças não tenham sido estatisticamente significativas. Jordan \& Croom (1957) e Wray et al. (1979) também não encontraram diferenças estatísticas na conversão alimentar dos animais alimentados com farinha de pena ou com o farelo de soja, concordando, portanto, com os resultados deste experimento.

Como apenas a conversão alimentar apresentou diferenças estatísticas, foram realizadas mais duas análises com o intuito de identificar possíveis diferenças existentes entre os tratamentos. A primeira foi a de contrastes ortogonais, em que se comparou individualmente o tratamento FS- Farelo de Soja com os outros quatro tratamentos. Depois, juntou-se os tratamentos que possuíam as mesmas fontes protéicas, ou seja, os tratamentos FPx com FPxU e os FPn com FpnU. Posteriormente, incluiu-se o tratamento com farelo de soja nessas comparações. Foram verificadas diferenças apenas no ganho de peso médio diário e na conversão alimentar, sendo elas descritas na Tabela 5 . Nesta tabela pode-se inferir que ocorreu diferença estatística em nível de 3\% entre os tratamentos com farinha de peixe e com farinha de pena para o ganho de peso médio diário, confirmando assim a tendência de maior ganho de peso proporcionado pelos tratamentos com farinha de peixe, ficando o tratamento com farelo de soja com um ganho de peso intermediário.

As diferenças na conversão alimentar determinada na Tabela 3 novamente são observadas na Tabela 5. Contudo, verifica-se diferença entre os tratamentos com farinha de peixe, em relação à farinha de pena, para conversão alimentar, em um nível de significância de 0,0001 , e entre a dieta com farelo de soja, em relação aos tratamentos com as farinhas de peixe, de 0,0004, confirmando-se novamente a tendência de menor consumo das dietas com farinha de peixe, associado ao maior ganho de peso verificado na Tabela 4. O farelo de soja promoveu conversão alimentar estatisticamente semelhante à dos tratamentos com farinha de pena.

A segunda análise realizada foi a do fatorial $2 \times 2$, sendo dois níveis protéicos (tratamentos FPx e FPn com $18 \%$ Vs FPxU e FPnU com 16\% de PB) e duas fontes protéicas (tratamentos FPx e FpxU com farinha de peixe Vs FPn e FPnU com farinha de pena), incluindo-se também nesta análise o tratamento com farelo de soja como um referencial - padrão. Assim, 
Tabela 5 - Comparação das variáveis ganho de peso médio diário (GMD) e conversão alimentar (CA), através da análise de contrastes ortogonais, referente aos tratamentos FS, FPx, FPn, FPxU e FpnU1

Table 5 - Comparison of the variables daily weight gain (DWG) and feed:gain ratio (FGR), through the analysis of contrasts ortogonais, for the treatments SM, FsM, FeM, FsMU and FeMU1

\begin{tabular}{|c|c|c|c|c|}
\hline $\begin{array}{l}\text { Contraste } \\
\text { Contrast }\end{array}$ & $\begin{array}{c}\text { Grau liberdade } \\
\text { Degree of freedom }\end{array}$ & $\begin{array}{l}\text { Quadrado médio } \\
\text { Mean square }\end{array}$ & $\begin{array}{l}\text { Valor } \mathrm{F} \\
\text { F Value }\end{array}$ & $\begin{array}{l}\operatorname{Pr}>\mathrm{F} \\
\operatorname{Pr}>F\end{array}$ \\
\hline \multicolumn{5}{|l|}{ GMD } \\
\hline$D W G$ & & & & \\
\hline FS vs FPx FPn FPxU FPnU & 1 & 0,0081 & 0,29 & 0,59 \\
\hline$S M$ vs FsM FeM FsMU FeMU & & & & \\
\hline $\begin{array}{l}\text { FPx FPxU vs FPn FpnU } \\
F s M F s M U \text { vs FeM FeMU }\end{array}$ & 1 & 0,1443 & 5,17 & $0,03 *$ \\
\hline $\begin{array}{l}F s M \text { FsMU } v s \text { FeM FeMU } \\
\text { FS vs FPx FpxU }\end{array}$ & 1 & 00564 & 202 & 017 \\
\hline$S M$ vs FsM FsMU & & & & 0,17 \\
\hline FS vs FPn FpnU & 1 & 0,0053 & 0,19 & 0,67 \\
\hline $\begin{array}{l}S M \text { vs } F e M \text { FeMU } \\
\text { CA }\end{array}$ & & & & \\
\hline$F G R$ & & & & \\
\hline $\begin{array}{l}\text { FS vs FPx FPn FPxU FPnU } \\
S M \text { vs FsM FeM FsMU FeMU }\end{array}$ & 1 & 0,4928 & 5,75 & 0,0264 \\
\hline $\begin{array}{l}\text { FPx FPxU vs FPn FPnU } \\
F s M F s M U \text { vs FeM FeMU }\end{array}$ & 1 & 2,2849 & 26,66 & $0,0001 * *$ \\
\hline $\begin{array}{l}\text { FS vs FPx FpxU } \\
S M \text { vs FsM FsMU }\end{array}$ & 1 & 1,5824 & 18,46 & $0,0004 * *$ \\
\hline $\begin{array}{l}\text { FS vs FPn FpnU } \\
S M \text { vs FeM FeMU }\end{array}$ & 1 & 0,0006 & 0,01 & 0,9362 \\
\hline
\end{tabular}

${ }^{1}$ FS - farelo de soja, FPx - farinha de peixe, FPn - farinha de pena, FpxU - farinha de peixe mais uréia, FpnU - farinha de pena mais uréia.

1 SM - soybean meal, FsM - fish meal, FeM - feather meal, FsMU - fish meal more urea, FeMU - feather meal more urea.

* , ** Significativo a 5 e $1 \%$ de acordo com teste $\mathrm{F}\left({ }^{*},{ }^{* *}\right.$ Significant at 5 and $1 \%$ by $F$ test $)$.

o desempenho proporcionado pelos outros tratamentos foi determinado em relação ao farelo de soja, sendo este expresso em percentagem. Apenas o consumo de matéria seca, expresso em $\mathrm{kg} / \mathrm{dia}$, foi estatisticamente igual em relação ao nível, a fonte e a interação nível vs fonte. Já o consumo de matéria seca em relação a peso vivo, peso metabólico, ganho de peso médio diário e conversão alimentar apresentou diferenças estatísticas pelo menos para um dos fatores, sendo estes descritos na Tabela 6 .

Verifica-se que o consumo de matéria seca em relação ao peso vivo foi igual entre a dieta com o farelo de soja e as dietas calculadas de acordo com o sistema de PM (com 16\% de PB). Já as dietas calculadas de acordo com o sistema de PB (com 18\% de $\mathrm{PB}$ ) foram cerca de $7 \%$ menos consumidas que o tratamento com farelo de soja. No entanto, as dietas calculadas pelo sistema de PM foram mais consumidas e estatisticamente diferentes daquelas calculadas pelo sistema de PB. Esses resultados indicam que os tratamentos FS, FPxU e FPnU possuíam adequada quantidade de nitrogênio degradável em nível ruminal, e os tratamentos FPx e FPn possivelmente promoveram menores consumos devido à menor palatabilidade e talvez à menor quantidade de nitrogênio potencialmente degradável, sendo isso resultado da elevada quantidade desses alimentos na dieta, associada à sua característica de baixa degradabilidade ruminal. Quando se compararam as fontes protéicas, verificou-se que os tratamentos com farinha de pena tiveram o mesmo consumo que o tratamento com o farelo de soja, porém as dietas com a farinha de peixe foram estatisticamente menos consumidas que as dietas com farinha de pena.

Na Tabela 6, verifica-se também que os consumos de matéria seca em relação ao peso metabólico foram diferentes apenas nos sistemas de cálculo de rações, ou seja, nos níveis protéicos. Portanto, as dietas contendo as farinhas de peixe e pena calculadas pelo sistema de $\mathrm{PB}$ foram menos consumidas que aquelas calculadas pelo método de PM, possuindo ainda consumo $7 \%$ menor que o tratamento com farelo de soja, confirmando novamente a possível deficiência de nitrogênio degradável no rúmen das dietas FPx e FPn. As dietas calculadas pelo sistema de proteína metabolizável também proporcionaram consumo igual ao tratamento com o farelo de soja. Verifica-se que os ganhos de peso foram iguais para 
Tabela 6 - Comparação dos consumos de matéria seca expressos em relação a peso vivo (CMSPV) e peso metabólico (CMSPM), ganho de peso médio diário (GMD) e conversão alimentar (CA) do nível e da fonte, determinada através da análise de fatorial e teste de Tukey, incluindo a dieta com o farelo de soja como um tratamento - padrão, sendo expresso o CMSPV, CMSPM, GMD e CA em percentagem e em relação à dieta com o farelo de soja

Table 6 - Comparison of dry matter intake expressed in relation to the live weight gain (IDMLWG) and metabolic weight (IDMWM), daily gain (DGW) and feed:gain ratio (FGR) as affected by protein level and source, determined through the factorial analysis and Tukey test, incluing the diet with soybean meal as a standard treatment, being expressed in IDMLW, IDMWM, $D G W$ and $A C$ in percentage and in relation to diet with soybean meal

\begin{tabular}{|c|c|c|c|c|c|c|c|c|}
\hline $\begin{array}{l}\text { Variável } \\
\text { Variable }\end{array}$ & $\begin{array}{l}\text { GL } \\
D F\end{array}$ & $\begin{array}{l}\mathrm{QM} \\
S M \\
\end{array}$ & $\begin{array}{l}\mathrm{F} \\
F\end{array}$ & $\begin{array}{l}\operatorname{Pr}>\mathrm{F} \\
\operatorname{Pr}>F\end{array}$ & $\begin{array}{l}\text { Nível } \\
\text { Level }\end{array}$ & $\begin{array}{l}\text { Média } \\
\text { Average }\end{array}$ & $\begin{array}{l}\text { Fonte } \\
\text { Source }\end{array}$ & $\begin{array}{l}\text { Média } \\
\text { Average }\end{array}$ \\
\hline $\begin{array}{l}\text { CMSPV } \\
I D M L W G\end{array}$ & & & & & & & & \\
\hline $\begin{array}{l}\text { Nível } \\
\text { Level }\end{array}$ & 1 & 220,84 & 4,60 & $0,05^{*}$ & F. Soja & 100,00 & F.Soja & 100,00 \\
\hline $\begin{array}{l}\text { Fonte } \\
\text { Source }\end{array}$ & 1 & 241,97 & 5,05 & $0,04^{*}$ & $16 \% \mathrm{~PB}$ & $99,78^{a}$ & F. Pena & $99,94^{\mathrm{a}}$ \\
\hline $\begin{array}{l}\text { Nível vs Fonte } \\
\text { CMSPM }\end{array}$ & 1 & 54,18 & 1,13 & 0,30 & $18 \% \mathrm{~PB}$ & $93,14^{b}$ & F.Peixe & $92,98^{b}$ \\
\hline $\begin{array}{l}\text { IDMWM } \\
\text { Nível } \\
\text { Level }\end{array}$ & 1 & 319,03 & 4,71 & $0,04^{*}$ & F. Soja & 100,00 & & \\
\hline $\begin{array}{l}\text { Fonte } \\
\text { Source }\end{array}$ & 1 & 165,01 & 2,43 & 0,14 & $16 \% \mathrm{~PB}$ & $100,72^{\mathrm{a}}$ & & \\
\hline $\begin{array}{l}\text { Nível vs Fonte } \\
\text { GMD } \\
D G W\end{array}$ & 1 & 121,29 & 1,79 & 0,20 & $18 \% \mathrm{~PB}$ & $92,73^{b}$ & & \\
\hline $\begin{array}{l}\text { Nível } \\
\text { Level }\end{array}$ & 1 & 11,82 & 0,03 & 0,86 & & & F. Soja & 100,00 \\
\hline $\begin{array}{l}\text { Fonte } \\
\text { Source }\end{array}$ & 1 & 2492,23 & 6,28 & $0,02 *$ & & & F. Peixe & $117,04^{\mathrm{a}}$ \\
\hline $\begin{array}{l}\text { Nível vs Fonte } \\
\text { CA } \\
F G R\end{array}$ & 1 & 673,16 & 1,70 & 0,21 & & & F. Pena & $94,72^{b}$ \\
\hline $\begin{array}{l}\text { Nível } \\
\text { Level }\end{array}$ & 1 & 279,62 & 8,57 & $0,0099 *$ & F. Soja & 100,00 & F. Soja & 100,00 \\
\hline $\begin{array}{l}\text { Fonte } \\
\text { Source }\end{array}$ & 1 & 1919,66 & 58,84 & $0,0001 *$ & $16 \% \mathrm{~PB}$ & $93,56^{\mathrm{a}}$ & F. Pena & $99,62^{\mathrm{a}}$ \\
\hline Nível vs Fonte & 1 & 0,00 & 0,00 & 1,0000 & $18 \% \mathrm{~PB}$ & $86,09^{b}$ & F.Peixe & $80,03^{b}$ \\
\hline
\end{tabular}

* Significativo a $5 \%$ de acordo com o teste $\mathrm{F}$

Letras diferentes indicam diferenças significativas $(P<0,05)$ de acordo com o teste de Tukey.

* Significant at $5 \%$ by $F$ test.

Different letters indicate significant differences $(P<.05)$ by Tukey test.

a dieta com farelo de soja e as dietas calculadas pelos dois sistemas, havendo, contudo, diferenças entre as fontes protéicas, sendo as dietas com farinha de peixe superiores às dietas com farinha de pena, confirmando a tendência de maior ganho de peso desta fonte, conforme foi verificado na Tabela 4. As dietas com farinha de peixe proporcionaram ganho de peso $17 \%$ maior e as dietas com farinha de pena $5 \%$ menor que o tratamento com farelo de soja; contudo, essas diferenças não foram diferentes, sendo isso verificado na análise de contrastes na Tabela 5. Não houve diferenças entre as dietas calculadas pelos diferentes sistemas, e isso indica que, mesmo contendo em média $42 \%$ a menos de farinha de peixe ou pena, as dietas calculadas pelo sistema de PM permitiu ganhos semelhantes, indicando que a proteína microbiana sintetizada no rúmen mais os aminoácidos dietéticos que foram absorvidos diretamente no intestino foram suficientes para permitir desempenho semelhante entre as dietas calculadas pelos diferentes métodos.

A conversão alimentar, verificada na Tabela 6 , confirma os resultados observados na Tabela 4 . Entretanto, na análise fatorial verifica-se que os níveis de 18 e 16\% PB tiveram conversão alimentar 14 e $6 \%$ melhor que o tratamento com farelo de soja, respectivamente. Já as dietas com o nível de 18\% foram superiores àquelas com $16 \%$ de $\mathrm{PB}$, apresentando menor conversão alimentar. Em relação à fonte 
protéica, a conversão alimentar proporcionada pelas dietas com farinha de pena foi igual à do tratamento com farelo de soja, ao passo que os tratamentos com farinha de peixe tiveram conversão alimen$\operatorname{tar} 20 \%$ melhor que o tratamento com farelo de soja. As dietas com farinha de peixe também tiveram conversão alimentar melhor que as dietas com farinha de pena.

\section{Conclusões}

O sistema de cálculo de ração de proteína metabolizável proposto pelo AFRC (1993) permite elaborar dietas com menor nível de proteína bruta que o sugerido pelo NRC (1988), sem afetar o desempenho dos animais.

Os tratamentos com farinha de peixe proporcionaram maiores ganhos de peso diários, menores consumos de matéria seca em relação ao peso vivo e melhor conversão alimentar que os tratamentos com farinha de pena, e o tratamento com farelo de soja apresentou desempenho intermediário.

\section{Literatura Citada}

AGRICULTURAL AND FOOD RESEARCH COUNCILAFRC. Energy and Protein Requirements of Ruminants. An advisory manual prepared by the AFRC Technical Committee on Responses to Nutrients. CAB INTERNATIONAL / UK, 1993. 159p.

AGRICULTURAL RESEARCH COUNCIL-ARC. The Nutrient Requirements of Ruminants Livestock. Commonwealth Agricultural Bureaux, UK, 1980.351p.

ANNISON, E.F.; CHALMERS, M.I.; MARSHALL, S.B.M. et al. Ruminal ammonia formation in relation to the protein requirements of sheep. III- Ruminal ammonia formation with various diets. Journal of Agricultural Science, v.44, p.270, 1954

BAGG, J.G.; GRIEVE, D.G.; BURTON, J.H. et al. Effect of protein on growth of Holstein heifer calves from 2 to 10 months. Journal of Dairy Science, v.68, p.2929-2939, 1985.

BEEVER, D.E.; COTTRILL, B.R. Symposium: Protein systems for feeding ruminant livestock. Journal of Dairy Science, v.77, p.2031-2043, 1994.

BLAS, C.; GONZALES, G.; ARGAMENTERIA, A. Nutricion y alimentacion del ganado. Ediciones Mundi - Prensa, 1987. $451 \mathrm{p}$.

BROSH, A.; HOLZER, Z.; LEVY, D. The effect of source of nitrogen used for supplementation of high wheat silage diets for cattle. British Society of Animal Production, v.51, p.109-114, 1990.

BROW, W.F.; PATE, F.M. Cottonseed meal or feather meal supplementation of ammoniated tropical grass hay for yearling cattle. Journal of Animal Science, v.75, p.1666-1673, 1997.

CHALUPA, W. Rumen by pass and protection of proteins and aminoacids. Journal of Dairy Science, v.58, n.8, p.1198$1218,1975$.

R. Bras. Zootec., v.31, n.3, p.1571-1581, 2002 (suplemento)
CHALUPA, W., CHANDLER, J.E., BROW, R.E. Amino acid nutrition of growing cattle. Feed Proceedings, v.31, p.681, 1972.

CHURCH, D.C. Alimentos y alimentacion del ganado. Tomo: Hemisferio Sur, 1984. 404p.

CHURCH, D.C. EI rumiante: fisiologia digestiva y nutricion. Zaragoza: Acribia, 1993. 641p.

COMERFORD, J.W.; HOUSE, R.B.; HARPSTER, H. W. et al. Effects of forage and protein sources on feedlot performance and carcass traits of Holstein and cross beef steers. Journal of Animal Science, v.70, p.1022-1031, 1992.

DAVENPORT, G.M.; BOLING, J.A.; GAY, N. Performance and plasma amino acids of growing calves fed corn silage supplemented with ground soybeans, fish meal and rumen protected lysine. Journal of Animal Science, v.68, p.37733779, 1990.

DERRIG, R.G.; CLARK, J.H.; DOVIS, C.L. The effect of abomasal infusion of sodium caseinate on milk yield, nitrogen utilization and amino acid nutrition of the dairy cow. Journal of Nutrition, v.103, p.151, 1973.

ENGLAND, P.; GILL, M. The effect of fish meal and sucrose supplementation on the intake of grass silage and liveweight gain of young cattle. Animal Production, v.40, p.259-265, 1985.

FERGUSON, K.A.; HEMSLEY, J.A.; REIS, P.J. Nutrition and wool growth. The effect of protecting dietary protein from microbial degradation in the rumen. Australian Journal of Science, v.30, n.6, p.215-217, 1967.

GARSTANG, J.R.; THOMAS, C.; GILL, M. The effect of supplementation of grass silage with fish meal on intake and performance by British Friesian calves. Animal Production, v.28, n.3, p.423, 1979. (Abstract)

GOEDEKEN, F.K.; KLOPFENSTEIN, T.J.; STOCK, R.A. et al. Hydrolyzed feather meal as a protein source for growing calves. Journal of Animal Science, v.68, p.2945-2953, 1990a.

GOEDEKEN, F.K.; KLOPFENSTEIN, T.J.; STOCK, R.A. et al. Protein value of feather meal for ruminants as affected by blood additions. Journal of Animal Science, v.68, p.29362944, 1990b.

GONTIJO FILHO, R.; BIOND, P.; SCOTT, W.N. Efeito dos farelos de soja, de algodão e de farinha de peixe na alimentação de bezerros da raça leiteira. Boletim da Indústria Animal, v.34, n.2, p.223-230, 1977.

HASSAN, S.A.; BRYANT, M.J. The response of store lambs to dietary supplements of fish meal. II- Effects of forage to concentrate ratio. British Society of Animal Production, v.42, p.223-232, 1986.

JAURIS, G.C. Desempenho de bezerros da raça holandesa com substituição parcial do leite por dieta sólida com baixa degradabilidade ruminal. Santa Maria, RS:UFSM, 1998. 130p. Dissertação (Mestrado em Zootecnia), Universidade Federal de Santa Maria, 1998.

JORDAN, R.M.; JORDAN, P.S. Comparative value of feather meal and soybean meal as a protein supplements for fattening lambs. Journal of Animal Science, v.14, p.1211-1212, 1955.

JORDAN, R.M.; CROOM, H.G. Feather meal as a source of protein for fattening lambs. Journal of Animal Science, v.16, p.118-124, 1957.

KEYSERLINGK, G.E.M.vON; MATHISON, G.W. The effect of ruminal escape protein and ambient temperature on the efficiency of utilization of metabolisable energy by lambs. Journal of Animal Science, v.71, p.2206-2217, 1993. 
Mc DONALD, I.W. The extent of conversion of food protein to microbial protein in the rumen of the sheep. Journal of the Biochemistry, v.56, p.120-125, 1954.

NATIONAL RESEARCH COUNCIL-NRC. Nutrient requirements of beef cattle. 7.rev.ed., 1996. 233p.

NATIONAL RESEARCH COUNCIL-NRC. Nutrient Requirements of Dairy Cattle. 6.rev.ed., 1988. 157p.

PETIT, H.V.; LACHANCE, B.; DIÓRIO, D. The effect of protein sources on the growth and carcass characteristics of veal calves. Canadian Journal of Animal Science, v.71, p.409-416, 1991.

RAKES, A.H.; DAVENPORT, D.G.; PETTYJOHN, J.D. et al. Hydrolyzed feather meal as a protein supplement for lactating dairy cows. Journal of Dairy Science, v.51, n.10, p.17011702, 1968.

REIS, P.J.; SCHINCKEL, P.G. Some effects of sulfur-containing amino acids on the growth and composition of wool. Australian Journal of the Biology Science, v.16, p.218230, 1963.

REIS, P.J.; SCHINCKEL, P.G. The growth and composition of wool. II- The effect of casein, gelatin and sulphur-containing amino acids given per abomasum. Australian Journal of the Biology Science, v.17, p.532-547, 1964.

ROCHA, A.; CARPENA, M.; TRIPLETT, B. et al. Effect of ruminally undegradable protein from fish meal on growth and reproduction of peripuberal Brahman bulls. Journal of Animal Science, v.73, p.947-953, 1995.

SILVA, D.J. Análise de alimentos (Métodos químicos e biológicos). Viçosa, MG: Universidade Federal de Viçosa, 1990. $160 \mathrm{p}$.

SAS INSTITUTE. Statistical Analysis System. User's Guide. 4.ed. Cary: 1990. 890p.

SANDERSON, R.; THOMAS, C.; Mc ALLAN, A.B. Fish meal supplementation of grass silage given to young growing steers: Effect on intake, apparent digestibility and liveweight gain. British Society of Animal Production, v.55, p.389-396, 1992.

SLOAN, B.K.; ROWLINSON, P.; ARMSTRONG, D.G. The influence of a formulated excess of rumen degradable protein or undegradable protein on milk production in dairy cows in early lactation. British Society of Animal Production, v.61, p.13-22, 1988.

SMITH, T.; SIVITER, J.W.; MERRY, R.J. Further comparisons of energy and protein sources for growing cattle. Journal of Agricultural Science, v.104, p.485-491, 1985.

STEEN, R.W.J. A comparison of soybean meal, fish meal and maize gluten feed as protein sources and offered grass silage ad libitum. Animal Production, v.54, p.333-339, 1992.
STEEN, R.W.J. A comparison of soybean, sunflower and fish meal as protein supplements for yearling cattle offered grass silage-based diets. British Society of Animal Production, v.48, p.81-89, 1989.

STEEN, R.W.J. Protein supplementation of silage-based diets for calves. British Society of Animal Production, v.41, p.293-300, 1985.

THOMAS, C.; GILL, M.; AUSTIN, A.R. The effect of supplements of fish meal lactic acid on voluntary intake of silage by calves. Grass and Forage Science, v.35, p.275279, 1980.

Van SOEST, P.J. Nutritional ecology of the ruminant. 2.ed. Ithaca: Cornell University, 1994. 476p.

VEIRA, D.M.; BUTLER, G.; IVAN, M. et al. Utilization of grass silage by cattle: effect of barley and fish meal supplements. Canadian Journal of Animal Science, v.65, p.897-903, 1985.

VEIRA, D.M.; BUTLER, G.; PROULX, J.G. et al. Utilization of grass silage by cattle: Effect of supplementation with different sources and amounts of protein. Journal of Animal Science, v.72, p.1403-1408, 1994.

VEIRA, D.M.; MACLEOD, G.K.; BURTON, J.H. et al. Nutrition of the weaned Holstein calf. I- Effect of dietary protein level on rumen metabolism. Journal of Animal Science, v.50, n.5, p.937-944, 1980a.

VEIRA, D.M.; MACLEOD, G.K.; BURTON, J.H. et al. Nutrition of the weaned Holstein calf. II- Effect of dietary protein level on nitrogen balance, digestibility and feed intake. Journal of Animal Science, v.50, n.5, p.945-951, 1980 b.

WHITE, T.W.; BUNTING, L.D.; STICKER, L.S. et al. Influence of fish meal and supplemental fat on performance of finishing steers exposed to moderate or high ambient temperatures. Journal of Animal Science, v.70, p.3286-3292, 1992.

WRAY, M.I.; BEESON, W.M.; PERRY, T.W. Effect of soybean, feather and hair meal protein on dry matter, energy and nitrogen utilization by growing steers. Journal of Animal Science, v.50, n.4, p.581-589, 1980.

WRAY, M.I.; BEESON, W.M.; PERRY, T.W. et al. Effect of soybean, feather and hair meals and fat on the performance of growing-finishing beef cattle. Journal of Animal Science, v.48, n.4, p.748-757, 1979.

ZERBINI, E.; POLAN, C.E. Protein sources evaluated for ruminating Holstein calves. Journal of Dairy Science, v.68, p.1416-1424, 1985. 